\title{
Educational Challenges of Pupils with Orthopaedic and Visual Impairment in Sokoto State, Nigeria
}

\author{
Asiyatu Abubakar Bagudo, Yinusa Abdulrafiu Yinka \\ Department of Adult Education and Extension Services, Usmanu Danfodiyo University, Sokoto, Nigeria
}

\begin{abstract}
This study investigated the educational challenges of pupils with orthopaedic and visual impairment in primary schools in Sokoto Central Educational Zone of Sokoto State, Nigeria. A quantitative survey study design was employed for the study. The purposive sampling technique was used to select 72 pupils with orthopaedic impairment and 89 pupils with visual impairment, making it 161 respondents at one special school and 20 inclusive primary schools within Sokoto Central Educational Zone. An adapted structured questionnaire was used for data collection, while a simple percentage was used in analyzing the data. The study's findings revealed that there were insufficient learning materials for the pupils with orthopaedic and visual impairment, lack of specially trained teachers, inaccessible infrastructures among others. The Study recommended that a module on special need conditions and inclusive education should be made compulsory for that all teacher training programmes. The government and Universal Basic Education should colloborate with development partners to provide adequate structures, infrastructures and all other facilites to meet the educational need of pupils with orthopeadic and visual challenges.
\end{abstract}

\section{INTRODUCTION}

$\mathrm{T}$ The education of exceptional children is a challenging field. However a society committed to the welfare of its people cannot ignore special sections like the physically challenged people. The ever-growing population gives rise to numerous problems in many spheres of life, the problem of being physically challenged is an important one. According to Tiwari in Beena (2007), "Being physically challenged is such a situation in which a person's normal behaviour, movement, and routine work are affected, and it creates physical, mental, social and emotional disorders in their behaviour which make them different from a normal people".

Educational challenges refer to problems facing students or pupils in educational settings that hinder their effective participation in school activities and outside the school environment. These problems serve as determinant factors that lead to the poor academic performance of student's or pupils at schools. The problems range from students' factors, school factors, environmental factors, socio-economic background of the parents, e.t.c. Oladejo and Oladejo (2011) observed that the first educational challenge is the challenge of the general inadequacy of educational funding. Nigerian education is not adequately funded, and this also affects the education of students with disabilities. Meanwhile, Psychosocial comes from the words, psychological and social interrelationship of the psychological aspects about the thoughts, feelings, reactions, and behaviours of a person with the social aspect about the situation, circumstances, events, relationship with others which influence or affect the person in sometimes to the point of causing distress.

Children with orthopaedic impairment have all varieties and degrees of difficulties in physical movement. Katsiyannis, Yell, and Bradley (2001) also asserted that orthopaedic impairment means a severe impairment that adversely affects a person's educational performance. The term includes impairments due to the effects of congenital anomaly (e.g., clubfoot), impairments due to the effects of the disease (e.g.,poliomyelitis, bone tuberculosis, etc.), and impairments from other causes (e.g., cerebral palsy,amputations, and fractures or burns that cause contractures). Meanwhile, Wolman in Beena (2007) points out that crippling conditions have in common two significant characteristics; one is that the disability is visible to all, and the second is that there are impairments in movement. On the other hand, visual Impairments refer to the loss of vision, even when a person wears corrective lenses. In addition, visual impairments are the reduced vision caused by eye diseases, accidents or eye conditions present from birth. According to Lydia (2014), visual impairments include blindness that, even with correction, adversely affects a child's educational performance.

Meanwhile, impairment affects individuals in different ways. Not all effects of impairment are undesirable. It is a challenge and depresses some while acting as a motivating and predisposing factor. Human history is full of evidence to prove that given proper environment and opportunity, orthopedically and visually impaired persons shape their destinies and significantly contribute to human civilization. For instance, in 2016, more than eleven Paralympics made Nigeria proud with eight gold medals at Rio Paralympic Games in Brazil. Among them is Ezuruike Roland, powerlifter, who set three Paralympics records. Kehinde Paul broke the men's $65 \mathrm{~kg}$ World record to win gold in the power-lifting event in 2016. Also, Barker in Beena (2007) revealed that President Franklin D. Roosevelt of the United States of American in 1933, who was a victim of poliomyelitis, yet steered the destinies of his people during the most crucial period of the world war. Likewise, Hellen Keller, in 1880, despite her double handicaps (deaf and blind), was instrumental in initiating effective measures for the welfare of the disabled throughout the world.

Also, John Milton, in 1608, was blind when he composed the voluminous piece of work called 'Paradise Lost'. Homer in 
$1184 \mathrm{BC}$ was also blind, and his famous works, namely 'the Iliad and Odyssey, were well known to the whole world. So it is clear that while exceptional person's cases are challenging in some circumstances, it is not so in some circumstances. As a result, it can be drawn out that physically challenged persons are not vocationally handicapped. If physically challenged persons are processed properly, the idea of placing right man to right job can easily be achieved, the need to focalize the victims of physically challenged persons and their problems have been the major constraint.

Education of the orthopedically and visually impaired pupils has national significance also; hence, there is the need to provide education suited to them. It will help prevent, reduce or eliminate the problems in academics, communication, locomotors, and adjustment of orthopedically and visually impaired children. Hussain, Bashir, Naseer, Naeem, Akter, and Inamula in Zaib \& Alia (2011) opined that the orthopedically and visually impaired pupils are just normal children. The only exception is their physical deformity; therefore, it is necessary to provide special facilities and the facilities provided to normal children.

To the best of the researcher's knowledge, there is no study conducted on educational and psychosocial challenges of pupils with orthopaedic and visual impairments in the case of primary schools in Sokoto Central Educational Zone, Sokoto State, Nigeria. Likewise, various stakeholders, including the local, urban administration, the family, the school and society, give not so much attention to it. For this reason, the study seeks to investigate educational and psychosocial challenges facing pupils with orthopaedic and visual impaired pupils in primary schools in Sokoto Central Educational Zone to ultimately suggest how to address the problems that the orthopaedically and visually impaired pupils encounter in such environments.

\section{Statement of the Problem}

The provision of free, equitable and quality education for all is a global goal, which was emphasized upon in the Jomtien conference in 1990, starting with basic education through Education for All (EFA) goals.In Nigeria as a signatory member country, it led to introduction of Universal Basic Education in 1999. Similarly, Kabuta (2014) asserted that The Universal Declaration of Human Rights in 1948 declared education as a fundamental right for every person, including people with disabilities. Therefore, physically challenged students, as clearly stated in the Convention on the Rights of Persons with Disabilities, which entered into force in 2008 and has 145 signatories, including Nigeria, were given more comprehensive chances for accessing education that will be friendly to the physically challenged persons. This includes making available all necessary environments supportive of the physically challenged students (including orthopedically and visually impaired pupils) at primary school and high level of education. Such support refers to excellent and supportive classrooms, laboratories, libraries, domitoris, internet connectivity, washrooms, dinning, and sports and games' spaces.

Because of the universal declaration of human rights (1948) and the Salamanca statement of 1994, the philosophies regarding children's education with physical disabilities have changed over the years. Several countries, including Nigeria, have led to implement policies that foster the integration of these learners, with physical disabilities, into mainstream environments. Here, the movement of integration and inclusive education has gained momentum in recent years due to global efforts.

However, implementating the above recommendations differs from one country to another and from one institution to another. The situation is worrisome in many developing countries, including Nigeria. This can result from poverty among countries or unfocused priorities and considerations given to quality education among disabled pupils. Despite the laws above that favour considering persons with disabilities, governments and stakeholders' priorities became a significant determinant when implementing the recommendations on how to give equitable, accessible and quality education to physically challenged students. This may be due to poor budgets in financial years on financing education to the pupils with special needs.

State Strategic Education Sector Plan (2010) revealed that Sokoto State, with a population of about 4 million, has a primary school-age population of about 1,100,000, 1963 public schools and an enrolment of $610,886(400,381 \mathrm{M}$; 210,505F). This gives a Net Enrolment Rate of 55.5\% and a Gross Enrolment Rate (GER) of $71 \%$. There are 12,737 teachers (M=9091, $\mathrm{F}=3646)$ while only 4247 (1246F) teachers are qualified which gives a teacher-pupil ratio of 1:47 and 1:144, respectively. The Net Attendance Rate for the current session (2009/10) is put at 68\%. The Completion and Gender Gap rates stand at $40 \%$ each at this session. This shows that $44.5 \%$ of the total school-age children were out of school in 2010. This data also shows a higher percentage of enrolment among boys $(69.8 \%)$ of school-age than girls (30.2\%). These are still lower than the National average of $86 \%$ for boys and $75 \%$ for girls. The biggest challenge to the state's realization of the Education for All (EFA) is the growing number of school-age children out of school despite the government's efforts to create additional structures through its expansion programme. It has been observed that there is a school-age population of about 1,100,000 at the Basic Education level. However, the Net Enrolment rate stands at 57\%, leaving about $43 \%(433,000)$ out of formal schooling in which pupils with orthopaedic and visual impairment are not exempted. These have all compounded the problem of access to special and inclusive schools in Sokoto Central Educational Zones in Sokoto State.

It is on this premise that the general objectives of this paper are to: 
i. Investigate the educational challenges of pupils with orthopaedic impairment in Sokoto Central Educational Zone, Sokoto State.

ii. Examine the educational challenges of pupils with visual impairment in Sokoto Central Educational Zone, Sokoto State.

\section{Review of Related Empirical Studies}

This section reviewed empirical studies which are relevant to this study. This study centred on educational and psychosocial challenges facing pupils with orthopaedic and visual impairment in primary schools. However, many works have been done on the issues of disability especially on physically (orthopaedic inclusive) and visually impaired pupils and this was discussed in line with the research questions and objectives of the study

\section{Studies on Educational Challenges of Pupils with Orthopedic Impairment}

Researches were conducted by various scholars on pupils with orthopaedic condtion. Samir and Kant (2013) conducted research on gender, achievement and locality of orthopedically impaired students. The researchers used a random sampling technique of 100 orthopedically impaired children to identify the different social problems of the children concerning their gender, achievement, and locality. A self-made questionnaire was used for the data collection. The study was limited to Moradabad and Bareilly commissionaire, while the study is limited to $08-14$ years of orthopedically impaired students only. The result shows that gender plays no vital role in social problems, but female impaired children have more problems than males. High achiever student has fewer social problems in comparison to their counterparts. The locality has no significant effect on social problems, but rural children have much more problem than urban children, which is due to unawareness and ignorance.

Buthelezi's (2014), study on explored challenges experienced by physically challenged students at further education and training college in KwaZulu-natal province. The population included six physically challenged students and four lecturers teaching physically challenged students at Mango FET College. Observations and semi-structured interviews were the main data-collection tools used in the study. The findings indicated that inaccessibility of buildings, lack of resources for physically challenged students, inadequate support from student support services and the college represented significant barriers to the success of the physically challenged students at Mango FET College in KwaZulu-Natal Province. Moreover, although student support services are available, the entire college population, students and staff alike, should all be responsible for creating an inclusive environment where students with physical challenges can experience a sense of community and attitudes of embracing diversity and accommodating differences.
Also, in the study of Mpofu and Almon (2012) on challenges students with special educational needs face in early childhood development centres in Zimbabwe as perceived by early childhood development trainers and parents. A survey design was used to assess these perceived challenges. Data were collected using questionnaires, interviews and observations checklist. A random sample of fifty (50) Early Childhood teachers, forty (40) females, ten (10) males and twenty (20) parents, ten (10) males, ten (10) females of children with special needs were used in this study. Data were analyzed using descriptive statistics and themes derived from research questions used in this study. The study found that untrained teachers were teaching children with special needs in ECD centres; these teachers were used as surrogate mothers at the centres, the school curriculum was inappropriate, and the physical environment was poor. As a result, children with special needs are learn under very challenging conditions in these centres.

As a result of these findings above, the researchers seeks to investigate the educational challenges of pupils with orthopaedic impairment in Sokoto Central Educational Zone, Sokoto State, Nigeria in order to improve the qualities of education of pupils with orthopaedic impairment in this area.

\section{Studies on Educational Challenges of Pupils with Visual Impairment}

The study by Kiomoka (2014) investigated the challenges children with Visual Impairments face in learning and participation in inclusive primary schools. First a qualitative case study design, specifically aimed to examine how the learning environment affects learners with visual impairments in inclusive primary school. Second, to explore the social interaction of learners with visual impairments in learning and participation in inclusive schools. Purposive sampling was adopted, and one school was selected from one municipality in Tanzania. The study involved 15 visually impaired students, ten sighted learners, and six teachers. Thus the sample size included 31 respondents. The data were collected through semi-structured interviews and non-participant observation. The data were subjected to transcription and thematic analysis, of which the results are presented per themes, categories, and direct quotes.

The study's findings revealed insufficient teaching and learning resources, shortage of teachers, exceptionally specially trained teachers and unfavourable physical environments. The findings further showed that there was also poor cooperation among teachers themselves and between them and parents. It was also revealed that there was a high rate of stigmatization to learners with visual impairments. On the other hand, the findings also showed no affirmative policy on inclusive education in the country. Based on the findings, the investigator recommends that there is a need for the Ministry of Education and Vocational Training (MEVT) and different stakeholders to collaborate and show their commitment in the provision of inclusive education by providing enough and relevant materials for the learners with 
disabilities; recruiting more teachers (especially the specialized ones in inclusive education), and making sure that the developed curriculum is flexible enough to meet the needs of each individual learner. The investigator further recommends that more education is provided to the parents of children with visual impairments and other forms of disabilities on the importance of educating their children. Also, the policy planners should incorporate inclusive education into the curriculum for general teachers' education.

Also, the research conducted by Rosalia (2014) revealed that the majority of public primary schools have inadequate or lack relevant physical facilities for the physically challenged learners like levelled doorsteps, lowered door handles, ramps, staircase rails and adapted toilets. It was also discovered that in the majority of the public primary schools, the teaching and learning resources are inadequate. From the study's findings, most teachers in public primary schools are not trained in handling physically challenged learners. Therefore, the teachers are unable to involve them in the learning process. The study concluded that regular public primary schools have unfriendly environments that hinder physically challenged learners' movement and participation. Most public primary schools cannot involve the physically challenged learners' movement and participation. Most public primary schools cannot involve physically challenged learners in their schools due to a lack of required teaching and learning materials. Most of the regular public primary school teachers do not have the skills required to handle physically challenged learners. As a result of the empirical studies on educational challenges of visually impaired pupils above, the researcher, therefore, seeks to investigate educational challenges of pupils with visual impairment in Sokoto Central Educational Zone, Sokoto State, Nigeria, in order to improve the qualities of education of the pupils with visual impairment in this area.

Below this paper now turn to the presentation and discussion of findings.

\section{DATA PRESENTATION AND ANALYSIS}

This chapter contains the presentation and analysis of data which starts with the respondents' bio-data, interpretation of the findings from research questions, a summary of discussion and discussion of the findings.

Presentation of Pupils' Bio-Data
This section presents information on the bio-data of the pupils with orthopaedic and visual impairment that constituted the respondents in this research. This section contains a table showing the types of school, sex, and types of impairment (orthopaedic and visual impairment)

Table 2: Showing Pupils' Bio-data

\begin{tabular}{|c|c|c|c|c|c|}
\hline & & \multicolumn{2}{|c|}{$\begin{array}{c}\text { Orthopedically } \\
\text { Impaired }\end{array}$} & \multicolumn{2}{c|}{$\begin{array}{c}\text { Visually } \\
\text { Impaired }\end{array}$} \\
\hline Items & Categories & $\mathrm{F}$ & $\%$ & $\mathrm{~F}$ & $\%$ \\
\hline School & $\begin{array}{c}\text { Mixed Boarding } \\
\text { School }\end{array}$ & 20 & $27.8 \%$ & 10 & $11.2 \%$ \\
\hline & $\begin{array}{c}\text { Mixed Day } \\
\text { School }\end{array}$ & 52 & $72.2 \%$ & 79 & $88.8 \%$ \\
\hline & Total & 72 & $100.0 \%$ & 89 & $100.0 \%$ \\
\hline Sex & Male & 54 & $75.0 \%$ & 67 & $75.3 \%$ \\
\hline & Female & 18 & $25.0 \%$ & 22 & $24.7 \%$ \\
\hline & Total & 72 & $100.0 \%$ & 89 & $100.0 \%$ \\
\hline
\end{tabular}

Source: Field survey, 2018

Table 4.1 indicates that the male pupils are the dominant sex in the two types of impairment (orthopaedic and visual) in the Sokoto Central Educational Zone. The result shows that 54(75.0\%) of the pupils with orthopaedic impairment were male, while $18(25 \%)$ were females. Also, $67(75.3 \%)$ of the respondents are males for the pupils with visual impairment, while $22(22.7 \%)$ of the respondents are females. This implies that regardless of the type of impairment, the majority of the pupils with orthopaedic and visual impairment are males in primary schools within Sokoto Central Educational Zone.

Based on the types of the school attended by the respondents, most pupils of both categories involved (orthopaedic and visual impairment) attend mixed day school in Sokoto Central Educational Zone. However, a substantial number of 52 (72.2\%) of pupils with orthopaedic impairment were in the mixed day schools, while 20 (27.8\%) of these pupils attended the mixed boarding school. In addition, there were 79 (88.8\%) of pupils with visual impairment in the mixed day schools while only $10(11.2 \%)$ of these pupils can be found in mixed boarding schools in Sokoto Central Educational Zone. Therefore, many pupils are found in mixed day schools against the pupils in a particular school. Thus, the only one special school which happens to be the only boarding school where pupils with orthopaedic and visual impairment can be found in Sokoto Central Educational Zone does seem not enough to accommodate pupils with challenging conditions.

Table 1: Educational Challenges of Pupils with Orthopedic Impairment

\begin{tabular}{|c|c|c|c|c|c|c|c|c|c|}
\hline \multirow{2}{*}{ S/No } & \multirow{2}{*}{ Items } & \multicolumn{2}{|c|}{ SD } & \multicolumn{2}{|c|}{$\mathrm{D}$} & \multicolumn{2}{|c|}{ A } & \multicolumn{2}{|c|}{ SA } \\
\hline & & $\mathrm{F}$ & $\%$ & $\mathrm{~F}$ & $\%$ & $\mathrm{~F}$ & $\%$ & $\mathrm{~F}$ & $\%$ \\
\hline 1. & My school is far from home & 7 & $9.7 \%$ & 14 & $19.4 \%$ & 27 & $37.5 \%$ & 24 & $33.3 \%$ \\
\hline 2. & $\begin{array}{l}\text { My classroom is overcrowded that I cannot participate in } \\
\text { reading and writing in the class }\end{array}$ & 21 & $29.2 \%$ & 25 & $34.7 \%$ & 18 & $25.0 \%$ & 8 & $11.1 \%$ \\
\hline 3. & $\begin{array}{l}\text { The method of teaching used by my teacher makes it } \\
\text { difficult for me to understand the lesson. }\end{array}$ & 29 & $40.3 \%$ & 20 & $27.8 \%$ & 14 & $19.4 \%$ & 9 & $12.5 \%$ \\
\hline
\end{tabular}


International Journal of Research and Innovation in Social Science (IJRISS) |Volume VI, Issue I, January 2022 |ISSN 2454-6186

\begin{tabular}{|c|c|c|c|c|c|c|c|c|c|}
\hline 4. & $\begin{array}{l}\text { During the examination, my teacher gives me extra time } \\
\text { than my regular classmates }\end{array}$ & 41 & $56.9 \%$ & 27 & $37.5 \%$ & 3 & $4.2 \%$ & 1 & $1.4 \%$ \\
\hline 5. & $\begin{array}{l}\text { My teacher pays more attention to me in the class } \\
\text { compare to normal pupils }\end{array}$ & 29 & $40.3 \%$ & 24 & $33.3 \%$ & 9 & $12.5 \%$ & 10 & $13.9 \%$ \\
\hline 6. & My parents assist me in doing my homework & 5 & $6.9 \%$ & 19 & $26.4 \%$ & 31 & $43.1 \%$ & 17 & $23.6 \%$ \\
\hline 7. & My parents encourage me to come to school regularly & 22 & $30.6 \%$ & 22 & $30.6 \%$ & 22 & $30.6 \%$ & 22 & $30.6 \%$ \\
\hline 8. & $\begin{array}{l}\text { Voluntary organizations do render us assistance with } \\
\text { regard to instructional and medical facilities at the school. }\end{array}$ & 35 & $48.6 \%$ & 22 & $30.6 \%$ & 5 & $6.9 \%$ & 10 & $13.9 \%$ \\
\hline 9. & $\begin{array}{l}\text { My classmates talk to me and assist me in the classroom } \\
\text { if I don't clearly understand my teacher's message }\end{array}$ & 1 & $1.4 \%$ & 5 & $6.9 \%$ & 38 & $52.8 \%$ & 28 & $38.9 \%$ \\
\hline 10. & My physical condition deters my learning -ability. & 18 & $25.0 \%$ & 29 & $40.3 \%$ & 17 & $23.6 \%$ & 8 & $11.1 \%$ \\
\hline
\end{tabular}

Source: Field survey, 2018

Table 2 presented the educational challenges faced by 72 pupils with orthopaedic impairment in Sokoto Central Educational Zone. Considering whether there is a far distance between the pupils with orthopaedic impairment's home and school, it was observed that $27(37.5 \%)$ of the pupils with orthopaedic impairment agree that their home is far from school. In comparison, 7(9.7\%) of the pupils with orthopaedic impairment indicated the close between their homes and schools.Their responses suggest that distance is a significant challenge for pupils orthopaedic impairment in Sokoto Central Educational Zone. This may be due to the inconsideration of the pupils with orthopaedic impairment by administrators in sighting the schools.

Regarding to class overcrowding, it showed that 25 (34.7\%) disagree that their classes are overcrowded, while 8 (11.1) strongly agree that their classes are not significant. Hence, this implies that class overcrowding is not a challenge for the pupils with orthopaedic impairment in Sokoto Central Educational Zone.

Considering the method of teaching used by teachers of pupils with orthopaedic impairment, 29 (40.3\%) of the respondents strongly disagree that the teachers' method of teaching makes it difficult for them to understand their lessons. In comparison, $9(12.5 \%)$ of the respondents strongly agreed that their teachers' teaching method was unsatisfactory. By indications, the method of teaching used by teachers of the pupils with orthopaedic impairment is not one of the educational challenges the pupils encounter at school. This may be because the teachers give special treatment to these pupils in delivering the lessons.

Based on the respondents' belief in the time given during examination by their teachers, the majority of the respondents, $41(56.9 \%)$, strongly disagreed that their teachers do not give them extra time. While only $1(1.4 \%)$ respondent strongly agreed that his teacher gives extra time during the examination. The result indicated that the pupils' teachers with orthopaedic impairment give equal time to both standards and physically challenged pupils during examinations. Hence, the teachers do not consider their physically challenged pupils to assign extra time to those who are not supposed to be.

Regarding the attention given to the pupils with orthopaedic impairment, the majority of the respondents indicated that the teachers give them more attention in the class than normal pupils. The Majority, 29 (40.3\%) of the pupils with orthopaedic impairment, strongly agreed that their teachers give them more attention. In comparison, $9(12.5 \%)$ of the pupils disagreed that their teachers give them more attention compared to normal pupils in the class. Impliedly, the result showed that the teacher devote their time to the pupils, and the extra attention expected to be given to the orthopaedically impaired pupils by their teachers is never a challenge to these pupils.

Considering the parental assistance rendered to the pupils with orthopaedic impairment by their parents, especially in the area of their homework given at school, it showed that a substantial number, 31 (43.1\%) of the respondents, agreed that their parents assist them in their homework given to them at school. In comparison, only $5(6.9 \%)$ of the respondents strongly disagreed that their parents do not assist when giving homework at school. The result showed that parental assistance in helping pupils with orthopaedic impairment in their homework is not one of the significant challenges faced by pupils with orthopaedic impairment in the Sokoto Central Educational Zone.

Based on the parental encouragement given to pupils with orthopaedic impairment to attend school regularly, 39 $(54.2 \%)$ of the respondents agreed that their parents encourage them to attend schools regularly. In comparison, only 3 (4.2\%) of the respondents strongly disagreed that their parents encourage them to attend school regularly. The result indicated that parental attitude to education of the pupils with orthopaedic impairment is positive.This implies that parental attitude is not one of the banes contributing to the educational challenges of pupils with orthopaedic impairment in the Sokoto Central Educational Zone.

Considering the respondent's belief in the contribution of the voluntary organization to instructional materials and medical facilities at their various schools, the majority, 35 (48.6\%) of the respondents, strongly disagreed that voluntary organizations do not assist them regarding instructional materials and medical facilities at school. In comparison, only $5(6.9 \%)$ of the respondents agreed that voluntary organizations render them assistance regarding the medical facilities and instructional materials at their various schools. The finding revealed that voluntary organization does not render the pupils any assistance in the area of instructional 
materials and medical facilities needed for their educational pursuit. Impliedly, lack of contribution of voluntary agencies in the areas of instructional and medical facilities is one of the major challenges of pupils with orthopaedic impairment in Sokoto Central Educational Zone.

The table also reveals that substantial number, $38(52.8 \%)$ of pupils with orthopaedic impairement agreed that their normal classmates assist them in the classroom especially if they do not clearly understand their teachers messages. In contrast, only $1(1.4 \%)$ strongly disagreed that their normal classmates assist them in the classroom especially if they do not clearly understand their teachers message. This implies that children with impairement are assisted by their normal classmates in the class.

Meanwhile, considering how the pupils with orthopaedic impairments' consider thier conditions as hinderance to learning, majority $29(40.3 \%)$ of these pupils disagreed that their physical conditions deter their learnings at school, compared to only $8(11.1 \%)$ of the pupils who strongly agreed that their physical conditions affect their learnings in the classroom. This shows that pupils with orthopedic impairment in Sokoto Central Educational Zone do not consider their physical impairement as hinderance to thier educational pursuit. This implies adequate support, parental and teachers orientations,provision of educational facilities are needed to boost their education..

Examination of the educational challenges of pupils with visual impairment in Sokoto Central Educational Zone, Sokoto State

In respect to the second objective of this study, the paper presents a table that contains all the items that were used to measure educational challenges of pupils with visual impairment.This included problems faced by the pupils with visual impairment at school and at home.The school factors are infrastructures, instructional facilities, teacher and normal pupils' attitudes towards the visually impaired students.The home factors are the parental attitude and educational support to children with visual impairement at home which could affect their performances.

Table 2: Educational Challenges of Pupils with Visual Impairment

\begin{tabular}{|c|c|c|c|c|c|c|c|c|c|}
\hline $\mathrm{S} /$ & \multirow{2}{*}{ Items } & \multicolumn{2}{|c|}{ SD } & \multicolumn{2}{|c|}{$\mathrm{D}$} & \multicolumn{2}{|c|}{ A } & \multicolumn{2}{|c|}{ SA } \\
\hline $\begin{array}{l}\mathrm{N} \\
\mathrm{o}\end{array}$ & & $\mathrm{F}$ & $\%$ & $\mathrm{~F}$ & $\%$ & $\mathrm{~F}$ & $\%$ & $\mathrm{~F}$ & $\%$ \\
\hline 1. & My school is far from home & 7 & $7.9 \%$ & 21 & $23.6 \%$ & 32 & $36.0 \%$ & 29 & $32.6 \%$ \\
\hline 2. & The class is too large for me to participate & 23 & $25.8 \%$ & 41 & $46.1 \%$ & 13 & $14.6 \%$ & 12 & $13.5 \%$ \\
\hline 3. & There are no adequate facilities to enhance my learning at school. & 16 & $18.0 \%$ & 18 & $20.2 \%$ & 30 & $33.7 \%$ & 25 & $28.1 \%$ \\
\hline 4. & $\begin{array}{l}\text { My teacher uses a braille machine, tape recorder, stylus and slate } \\
\text { for me in the classroom }\end{array}$ & 62 & $69.7 \%$ & 19 & $21.3 \%$ & 3 & $3.4 \%$ & 5 & $5.6 \%$ \\
\hline 5. & My teacher is a specialist in handling visually impaired pupils & 34 & $38.2 \%$ & 22 & $24.7 \%$ & 13 & $14.6 \%$ & 20 & $22.5 \%$ \\
\hline 6. & $\begin{array}{c}\text { My teacher does allow me to participate in educational } \\
\text { competitions }\end{array}$ & 11 & $12.4 \%$ & 27 & $30.3 \%$ & 32 & $36.0 \%$ & 19 & $21.3 \%$ \\
\hline 7. & $\begin{array}{c}\text { During the examination, my teacher gives me extra time because } \\
\text { of my sight problem }\end{array}$ & 39 & $43.8 \%$ & 24 & $27.0 \%$ & 12 & $13.5 \%$ & 14 & $15.7 \%$ \\
\hline 8. & $\begin{array}{l}\text { I can read by braille equally with my sighted friends who can read } \\
\text { by the print reader }\end{array}$ & 57 & $64.0 \%$ & 22 & $24.7 \%$ & 5 & $5.6 \%$ & 5 & $5.6 \%$ \\
\hline 9. & $\begin{array}{l}\text { I am worried about the studies that I cannot cope with education } \\
\text { demands on me }\end{array}$ & 22 & $24.7 \%$ & 30 & $33.7 \%$ & 19 & $21.3 \%$ & 18 & $20.2 \%$ \\
\hline 10. & My parents assist me in doing my homework at home & 13 & $14.6 \%$ & 35 & $39.3 \%$ & 18 & $20.2 \%$ & 23 & $25.8 \%$ \\
\hline
\end{tabular}

Source: Field survey, 2018

Table 2 presented the educational challenges faced by 89 pupils with visual impairment in the Sokoto Central Educatonal Zone. Considering whether there is a far distance between the pupils with visual impairment's home and school, it was observed that $32(36.0 \%)$ of the pupils with orthopaedic impairment agree that their home is far from school. In comparison, $7(7.9 \%)$ of the pupils with orthopaedic impairment strongly disagree that the distance between their homes and schools is far from home. Their responses suggest that distance is one of the major educational challenges of pupils with visual impairment in the Sokoto Central Educational Zone. This may be due to the inconsideration of the pupils with visual impairment by administrators in sighting the schools.
Regarding whether the classes of pupils with visual impairment are overcrowded for them to participate in teaching and learning activities, it showed that $41(46.1 \%)$ of the pupils disagree that their classes are overcrowded for them to participate in the teaching and learning activities. In comparison, only $12(13.5 \%)$ of the pupils strongly agree that their classes are too large for them to participate. Hence, this implies that class overcrowding is not one of the significant challenges faced by puplis with visual impairment in Sokoto Central Educational Zone.

Considering whether there are no adequate facilities to enhance pupil's learning with visual impairment in Sokoto Central Educational Zone, specifically, 30 (33.7\%) of the pupils agreed that there are no adequate facilities to enhance 
their learnings. In comparison, $16(18.0 \%)$ strongly disagree that there are no adequate facilities to enhance their learnings. Therefore, the result showed that the lack of adequate facilities to enhance pupil's learning with visual impairment is one of their educational challenges in the Sokoto Central Educational Zone.

The majority of the respondents, $62(69.7 \%)$, strongly disagreed that their teachers use instructional facilities like braille machines, tape recorder, stylus, and slate in classrooms. In comparison, only $3(3.4 \%)$ of the respondents agreed that the teachers used the instructional facilities for them in the classroom. Impliedly, the result indicated that lack of instructional facilities is one of the major educational challenges of the pupils with visual impairment in Sokoto Central Educational Zone.

Considering whether the teachers in Sokoto Central Educational zone are specialists in handling pupils with the visually impaired, 34 (38.2\%) of the respondents strongly disagreed that their teachers are specialists in handling their classes. In comparison, 13 (14.6\%) of the respondents agreed that their teachers are specialists in handling their classes in the Sokoto Central Educational zone. The result showed that the specialists handling the visually impaired pupils are one of the significant educational challenges of these pupils in Sokoto Central Educational Zone.

Regarding wether teachers do allow pupils with visually impairment to participate in educational competetions like quiz and debate at school.The table reveals that a substantial number, $32(36.0 \%)$ of the respondents, agreed that their teachers allow them to participate in educational competitions at school. In comparison, $11(12.4 \%)$ of the respondents strongly disagreed that their teachers allow them to participate in educational competitions at school. Impliedly, the result shows that pupils with visually impairement participation in an educational competition like quiz and debate are not one of the educational challenges of visually impaired pupils in the Sokoto Central Educational Zone. This is due to the teachers' consideration of these pupils in selecting the participants in educational competitions at their various schools.

The table also reveals that the majority of the respondents, 39 (43.8\%), strongly disagreed that their teachers give them extra time during examination because of their visual problems. In comparison, $11(12.42 \%)$ of the respondents strongly disagreed that their teachers give them extra time during examinations because of their visual problems.The finding indicates that consideration of the pupils with visually impaired by their teachers during examination is one of the significant educational challenges faced by pupils with visually impaired pupils in Sokoto Central Educational Zone. This is due to giving the same time for visually and nonvisually impaired pupils during the examinations.

Considering whether pupils with visually impaired in Sokoto Central Educational Zone can read by braille equally with their sighted colleagues who can read by the print reader in the class, a substantial number of the respondents, (64.0\%) strongly disagreed that they can read by braille equally like their sighted colleagues can read print reader in the class. In contrast, a minority of the respondents, $(13.5 \%)$, agreed that they could read by braille equally with their sighted colleagues who can read by the print reader in their class. This implies that using a braille machine to read is one of the significant educational challenges of the pupils with visual impairment in the Sokoto Central Educational Zone. This is justifiable since there are inadequate instructional facilities for the pupils with visual impairment in Sokoto Central Educational Zone.

Also, substantial number of the respondents, 30 (33.7\%) disagreed that they are worried about their studies and cannot cope with their education demands. While a minority, 18 $(20.2 \%)$, of the respondents, strongly agreed that they are worried about their studies and cannot cope with their education demands. By implication, the result shows that the pupils with visual impairments' self-confidence are high that their visual conditions do not affect their learning at school in Sokoto Central Educational Zone.

Meanwhile, looking at parental care on the pupils' education with visual impairment in Sokoto Central Educational Zone,a substantial number of the respondents, 35 (39.3\%), disagreed that their parents assist them in doing their home works at home. In contrast, a minority of the respondents, 13 (14.6\%), strongly disagreed that their parents assist them in their home works at home. The result shows that parental commitment to the pupils' education with visual impairment is shallow; this may be a result of negligence on the parts of parents to their kids.

\section{SUMMARY OF THE FINDINGS}

1. The findings showed that educational challenges of pupils with orthopaedic impairment include a lack of instructional and social facilities for pupils with orthopaedic impairment.The other challenges are, the pupils' far distance between home and school, and lack of consideration for extra-time given to pupils with orthopaedic impairment during examinations. Others challenges are, lack of voluntary organization assistance concerning instructional and medical facilities, and lack of assistance to pupils with orthopedically impaired from their counterparts with the normal condition when the need arises.

2. The studies also revealed that educational challenges of pupils with a visual impairment include, inadequate specialist teachers, lack of instructional materials like braille, which leads to the inability of the pupils with visual impairment to read by braille. Other challenges are, inaccessible infrastructures for pupils with visual impairment, a far distance of pupils with a visual impairment from home to school, and lack of extra-time on the part of the teachers for pupils with visual impairment during examinations. 


\section{DISCUSSION OF THE FINDINGS}

This section presents a discussion on the finding of the research. The discussions are presented thematically according to the research objectives and research questions. The findings were discussed with relevant literature to either establish or refute the arguments of that literature as it relates to the study area.

Research question one revealed that educational challenges of pupils with orthopaedic impairment in Sokoto Central Educational Zone include lack of instructional facilities and support to pupils with orthopaedic impairment from their physically fit counterparts. This finding is in line with Buthelezi's (2014) finding which revealed that lack of resources for physically challenged students and inadequate support from student support services is one of the significant barriers to the success of physically challenged students at schools. Although, the finding contradict Hussain et al (2011) who revealed that normal students have good interaction with the physically disabled students, most of them were called by specific nick names.

Another educational challenge for pupils with orthopaedic impairment is their far distance between homes, where the pupils with orthopedic impairment reside and schools they attend. This was supported by the Awetash (2015) research that fears in moving long-distance and happy by getting an opportunity of education were the significant educational challenges of pupils with physical challenges. Also, among the educational challenges of pupils with orthopaedic impairment, are lack of extra-time given to pupils with orthopedic impairment during examinations and lack of voluntary organization assistance with regard to instructional and medical facilities. These findings correlates with that of Buthelezi's (2014), who suggested that the entire school population, students and staff alike, should all be responsible for creating an inclusive environment where students with physical challenges can experience a sense of community and attitudes of embracing diversity and accommodating differences.

Lack of instructional and social facilities for pupils with orthopaedic impairment is also one of the educational challenges of pupils. This finding was supported by the findings of Daniel (2008) that non-user friendly infrastructure, inadequate appropriate teaching and learning materials, inadequate funding to schools and long-distance to schools, are the challenges faced by pupils with physical challenges.

The findings from research question two found out that educational challenges of pupils with a visual impairment include lack of instructional and social facilities for pupils with visual impairment.Awetash (2015) similarly asserted that lack of braille materials, books in braille presented significant problem for pupils with visual impairment. This led to the inability of the pupils with visual impairment to read by braille equally with their non-visually impaired counterparts who can read by printed material. Similarly,
Rosalia (2014) found that most public primary schools had inadequate teaching and learning resources. Some also, lacked relevant physical facilities for the physically challenged learners such as levelled doorsteps, lowered door handles, ramps, staircase rails and accessible toilets, which are inadequate for pupils with visual impairment.

Other educational challenges for pupils with a visual impairment include inadequate specialist teachers. This finding correlates with findings made by Rosalia (2014) that the majority of teachers in public primary schools are not trained in handling physically challenged learners. Therefore, the teachers are unable to involve them in the learning process. Likewise, Mpofu and Almon (2012) found that untrained teachers were teaching children with special needs. He revealed that despite the teachers of the visually impaired pupils giving the necessary attention, the schools do not have instructional materials for teaching them. This finding was corroborated by Hussain et al. (2011) that the majority of the teachers gave special attention to them, but they do not have specific aids in the class room to teach them. According to Igune (2009), he also opined that most general teachers lacked the basic knowledge and skills to accommodate learners with visual impairment in the inclusive classrooms or even engage them in extra-curricular activities. In connection with this, assistance is esssential for learners with visual impairment. According to Vygoky's view, children can perform better when they have proper assistance from Gindis (1999). Moreover, good support between STs and GTs may make the pupils with visual impairment participate well in the learning process just like their fellow sighted peers.

\section{CONCLUSION}

Based on the findings on educational challenges of pupils with orthopaedic and visual impairment, it is concluded that both inclusive and special schools within Sokoto Central Educational Zone of Sokoto State have inadequate instructional materials for the pupils with orthopaedic and visual impairment, inaccessible infrastructures, lack of untrained specialist teachers, the far distance between the pupil's home and school, and lack of voluntary organization assistance with regard to instructional materials.

The conclusion is that educational challenges of pupils with orthopaedic and visual impairment are not due to orthopaedic and visual conditions itself, but mostly result from inadequacies in the attitudes, relationahips, supports and discriminations towards such pupils at schools and homes. Also, lack of basic infrastructures,equiptments and quality teaching-learning process as well as lack of medical facilities, health personnels and discriminatory attitude by the normal pupils are factors that constitute challenges to pupils with orthopedic and visual impairment. It is noted that pupils with orthopedic and visual impairment have self-confidences and capacities that need to boosted at school, at home, and all people interacting with them to remedy their educational challenges and support their educational pursuits. 


\section{RECOMMENDATIONS}

Based on the findings of the study, the following recommendations were made:

1. In collaboration with teacher training institutes the government should include a module on special needs conditions,inclusive education, best practices for people with special needs in training of all teachers.This will help them to understand the differences between children with and without disabilities. Such opportunities would enable teachers understand that all children can learn if given a chance.

2. In collaboration with Universal Basic Education Commission, the government must prepare particullar budgets to support or accommodate students withspecial needs and challenges. Especially the pupils with orthopaedic and visual impairment in Sokoto Central Educational Zone.

3. Universal Basic Education Commission (UBEC),Ministry of Education should strengthen synergies with International Development Partners(IDP) to provide quality structures, infrastructure and improve the existing schools, to construct ramps, wider classroom doors, and accessible toilets to make education accessible to suit the needs of pupils with orthopaedic and visual impairment in Sokoto Central Educational Zone.

4. It is recommended that parents, teachers,classmates and people around children with orthopaedic and visual impairments should develop positive attitudes,and support toward them very well and assist them in overcoming their challenges.

\section{REFERENCES}

[1] Awetash, F. (2015). Psychosocial and Educational Challenges and Opportunities of Students with Visual Impairment: The case of Adimahleka primary School in Adwa Town. Unpublished Thesis. College of Education and Behavioral Studies. Addis Ababa University.http://etd.aau.edu.et/123456789/11114

[2] Beena, K. (2007). Influence of Certain Socio-Psychological Factors on the Vocational Skill Attainment of Orthopedically
Handicapped Adolescents. Unpublished Thesis. School of Pedagogical Sciences, Mahatma Gandhi University.

[3] Buthelezi, M. (2014). Exploring Challenges Experienced by Physically Challenged Students at a Further Education and Training College in Kwazulu-Natal Province. Journal of Educational and Social Research. 4(3); 421-427.

[4] Daniel, N. (2008). Challenges Faced by Pupils with Disabilities in Accessing Education Inclusive Schools in Zambia. University of Zambia.

[5] Gindis, B. (1999). Vygotsky's Vision Reshaping the Practice of Special Education for the $21^{\text {st }}$ Century. Remedial and Special Education, 20(6), 333-340 .

[6] Hussain, I.; Bashir,M.;Naseerudin ,M.;Naeem,M.; Akhter,S. and Inamullah,A. (2011). Problems Faced by Physically Handicapped Students in Educational Institutes in District Kohat. Contemporary Issues in Education Research 4 (2): 23-26

[7] Igune, G. W. (2009). Inclusion of Blind Children in Primary Schools: a case study of teachers opinion in Moroto DistrictUganda. Oslo .https://www.duo.uio.no>

[8] Katsiyannis, A., Yell, M.L. and Bradley, R. (2001). Reflection on the $25^{\text {th }}$ anniversary of the individual with Disabilities Educational Act. Remedial and Special Education, 22(6), 324-334.

[9] Kiomoka, D. (2014). Children with Visual Impairment in Tanzania. An investigation of the challenges which children with Impairment Face in Learning and Participation in Inclusive Primary Schools. Unpublished thesis. Faculty of Education and Natural Sciences Hedmark University College.

[10] Lydia, A. (2014). Challenges Faced by Learners with Visual Impairment in Inclusive Setting in Trans-Nzoia Country, Kenya. Journal of Education and Practice, 5 (9), 16203-18529

[11] Mpofu J. \& Almon S. (2012). Challenges Faced by Students with Special Educational Needs in Early Childhood Development Centers in Zimbabwe as Perceived by ECD Trainers and Parents. Anthropologist 14 (4): 327-338

[12] Oladejo, M. \& Oladejo, S. (2011). Educating Students with Disabilities in Nigeria: Some Challenges and Policy Implications. Journal of Humanities and Social Sciences. 3 (1), 2220-9525

[13] Rosalia, W. (2014). School-Based Factors Influencing Participation of Physically Challenged Learners in Public Schools in Kiambu Municipality, Kenya. Unpublished Thesis. Curriculum Studies, University of Nairobi.

[14] Samir, K.L \& Kant, R. (2013). Problems of Orthopedically Impaired Students in Relation to their Gender, Achievement and Locality. Journal of Education and Social Research. 3 (2); 2031.

[15] State Strategic Education Sector Plan (2010) Situation Analysis of Education in Sokoto State.

[16] Zaib, N. \& Alia, S. (2011) Problems Faced by Physically Handicapped Students at Secondary School Level in District Kohat, M. Ed Thesis, Institute of Education and Research, Kohat University of Science \& Technology, Kohat, Pakistan. 